\title{
LA LÓGICA DE LA NOSTALGIA. HISTORIA Y CULTURA EN EL SIGLOXX.
}

Por Rodrigo Quesada Monge.

\author{
"La historia de una revolución fallida no es la \\ historia de un crimen".
}

K. Marx.

\section{PROLEGÓMENOS NECESARIOS.}

Este es un ensayo que consideramos indispensable. Muy raro, como puede sonar, pocos son los autores, los escritores, los historiadores o los analistas de la cultura, que se han preocupado, o sentido interesados, por la nostalgia como tema amplio de discusión y meditación filosófica. Eso puede deberse a razones de diversa naturaleza, entre ellas, al hecho de que la nostalgia evoca una obsesión improductiva por el pasado. Si ésto es totalmente cierto, el historiador debería someter a un cerrado escrutinio los postulados centrales de su profesión, en la medida en que todo estudio del pasado, a la larga, puede resultar improductivo; pues si partimos de la base de que el hombre es el único animal que no aprende de su experiencia, entonces, toda enseñanza histórica carece de significado práctico.

Se puede añadir que la nostalgia es un esfuerzo inútil por recuperar lo vivido, con la misma fuerza y emotividad de su expresión primera. En este caso, todo mirar atrás carece de enlaces realistas con el presente y nos deja perplejos ante la inmensa planicie del futuro. Así planteada, la nostalgia, es evocación del pasado, sin posibilidad de actuar sobre el presente para transformar el futuro.

Sin embargo, nosotros creemos que no es suficiente sostener que el objeto de nostalgia deje al sujeto en una situación de desabrido desamparo, y sólo le 
permita la alternativa de un presente desencantado e irreconciliable con el ayer y con el mañana. La nostalgia es la magia de la utopía, es el hechizo de una realidad que se quiso distinta y se nos evaporó en las manos. Pero precisamente en eso radica todo su poder. $Y$ esa es en efecto nuestra hipotesis de trabajo. Despleguémosla para una mayor comprensión del asunto que queremos compartir con nuestro lector.

1. Curiosamente, al mismo tiempo que el siglo $X X$ está repleto de grandes descubrimientos futuristas y altamente técnicos, es también un siglo nostálgico. Si recordamos a escritores como Marcel Proust, habitantes de los meros bordes del siglo, nos daremos cuenta que todo su proyecto estético reposa sobre la idea maravillosa de que sólo el arte puede salvar la memoria, y en consecuencia la vida.

2. Existe un objeto de nostalgia y un sujeto nostálgico. La nostalgia no es simplemente una emoción, un afecto, un sentimiento o un resentimiento. Es todas esas cosas juntas, y al mismo tiempo, es también una actitud frente a la vida; en especial la de todos los días.

3. Pero para que haya nostalgia debe haber un sujeto nostálgico que la experimenta y la hace posible con sus actos cotidianos, sus experiencias, sus acciones y reacciones. El psicoanálsis es por ejemplo, un método, entre muchos otros, para la reconversión productiva de la nostalgia.

4. Hay nostalgia porque hay experiencia. El sujeto la experimenta a través del fracaso, o de la frustración, de las acciones o emociones que fueron exitosas 
o productivas en el pasado, el cual se construye y se reconstruye desde el presente, para poder enfrentar al futuro.

5. Y para que esa reconstrucción del pasado sea viable, el sujeto nostálgico necesita de la utopía, una que es ya de por sí dolorosa desde el momento en que la realidad le ha demostrado al sujeto que ya cambió de dirección.

6. Con su cambio de naturaleza o de configuración, la realidad obliga al sujeto a reinventar la utopía, en cuyo caso aquella se vuelve también muy dolorosa. El sujeto nostálgico en consecuencia, es un sujeto que sufre.

Nosotros intentaremos con este ensayo reflexionar un poco sobre ese sufrimiento en particular, sus distintas manifestaciones y las diversas vías que han buscado los hombres para hacerlo tolerable, y por supuesto, productivo. El sufrimiento debe portar esta última condición, de lo contrario se convierte en tortura, en dolor inconsecuente.

\section{LAS PARADOJAS DE LA NOSTALGIA.}

Tomemos otra vez el ejemplo de la experiencia de Marcel Proust. Como cronista iluminado de la crisis de la aristocracia francesa de fines del siglo pasado y principios del presente, su monumental novela En busca del tiempo perdido ${ }^{1}$ es el mejor ejemplo que podríamos mencionar de lo que aquí llamaremos la añoranza culpable.

El que añora recuerda con gratitud y tristeza al amor, la amistad, el ideal o el objeto perdidos. Pero se siente culpable por no haber hecho lo suficiente para 
impedir que la pérdida se diera. Esa paradoja es increíblemente útil para entender el programa de vida de la persona que ha terminado atrapada por la nostalgia.

La paradoja permite examinar con cuidado y precisión los ideales de la primera parte del presente siglo. Y ello está maravillosamente bien retratado en el trabajo novelístico de Proust. Incluso en su vida personal, la alegría y la tristeza, la culpa y la templanza, la euforia y la depresión se turnaron, para llenar al novelista de un abanico de contradicciones poderosas y elocuentes de lo que sucedía con la política y el arte en los albores del siglo XX.

A la manera de los griegos, quienes hicieron de la paradoja una virtud, sin la cual es imposible comprender la paideia ${ }^{2}$ o los ideales sustanciales de su civilización, los hombres y mujeres de cultura del siglo XX, han hecho de la añoranza culpable una forma de vida cotidiana. La incertidumbre, el desamparo, la pérdida de certezas morales y políticas, hacen que la cultura de la primera parte del siglo no sea suficiente para llenar los enormes huecos existenciales de los hombres y mujeres de ese momento. Eso se llena en las calles, la taberna, el burdel, los parques. Hasta 1945, la cotidianidad sería la de las colectividades.

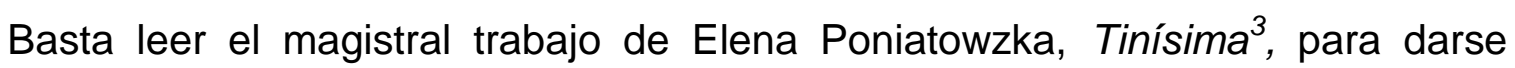
cuenta hasta dónde llegó la herencia de hombres como Proust, Kafka, Rilke, Pessoa y otros. No sólo en el sentido del quehacer cotidiano, sino fundamentalmente en el de la configuración de ideología. La experiencia del

\footnotetext{
${ }^{1}$ Existe una excelente traducción de los siete volúmenes, hecha por Alianza de España en diferentes momentos entre 1966 y 1982, de la versión original al francés de Gallimard (1919-1927).

${ }^{2}$ JAEGER, Werner. PAIDEIA: LOS IDEALES DE LA CULTURA GRIEGA (México: Fondo de Cultura Económica. Novena edición, 1987) Capítulo I, Nobleza y Areté. Pp.19-29. 
comunista al estilo de Tina Modotti es la del que quiere transformar la moral burguesa sirviéndose de ella. Nada podría haber sido más paradójico.

Pero es que la añoranza culpable de los años que median entre 1870 y 1918 , es la de los imperios, la del individuo, la del silencio y la espiritualidad divinizada por la creación literaria y artística en general. El político, además de un hombre de ideas, debe ser un artista, un buen orador, un mago habilidoso en el manejo de la intriga y las turbias relaciones entre los hombres y los estados. La primera parte del siglo está llena de ellos.

Se añora lo perdido y para amortiguar la culpa, se hace arte, poesía, pintura, música, se practica una forma de política en la que la culpa se socializa y desde las colectividades amorfas, grises y a veces brutales, se le hace creer al individuo que de esa manera puede conjurar sus demonios. La psicología de Freud está diseñada para salvar al individuo, no a las colectividades. La civilización en estos casos es un asunto del pasado, no del presente.

El nazismo y el stalinismo les manejaron a grandes masas humanas, una culpa heredada porque los padres o los abuelos no habían hecho lo suficiente para impedir los desafueros del presente. Pero el nazismo se apoyó mucho en la nostalgia del pasado, el stalinismo hizo lo mismo con la nostalgia del futuro. En todo caso el presente fue lo más volátil. Y ésto es irónico porque sólo se construye o se destruye desde el presente.

Con el afán de recuperar las glorias del pasado, los nazis destruyeron el presente de la Alemania de los años veinte y treinta. Algo similar les sucedería

\footnotetext{
${ }^{3}$ PONIATOWSKA, Elena. TINÍSIMA (México: ERA.1992).
} 
a los soviéticos, puesto que en su angustia por construir un futuro mejor y distinto al que ofrecían el capitalismo y la burguesía decadente, demolieron su propio pasado, y se quedaron sin posibilidad de construir el sueño que alguna vez les prometiera la revolución bolchevique. En ambos casos, el presente salió seriamente deteriorado y se convirtió en algo elusivo, inaprensible, una categoría temporal que no tiene estatuto teórico para la mayor parte de los pensadores burgueses contemporáneos; a no ser en las sociedades en desarrollo, donde el presentismo se mide según la dimensión alcanzada por el proyecto revolucionario.

Para la América Latina, por ejemplo, su presente lo definen la calidad y las potencias de los proyectos y movimientos revolucionarios vigentes. No podemos darnos el lujo de añorar culpablemente el pasado. Hay que construir el futuro, pero desde un presente explicado y comprendido a la perfección. No como hicieron los soviéticos, levantar la utopía de un futuro incierto sobre las montañas de cadáveres del presente. América Latina, o modifica su presente, o se queda sin futuro. Porque su pasado le pertenece a las potencias imperialistas.

De esta manera llegamos a la conclusión de que existen dos tipos de nostalgia, cada uno teñido por una clase diferente de añoranza culpable. La nostalgia imperialista ${ }^{4}$ de corte victoriano por ejemplo, trae consigo una añoranza que dio nombres como el de Oscar Wilde, con quien se cebó la culpabilidad burguesa. Por eso resultan ridículas, para decir lo menos, las poses

\footnotetext{
${ }^{4}$ ROSALDO, Renato. CULTURA Y VERDAD. NUEVA PROPUESTA DE ANÁLISIS SOCIAL. (México: Grijalbo. 1991) Pp.71-87. 
que asume un nostálgico pro-imperialista al estilo de Mario Vargas Llosa, porque éste es un intruso, en el tanto no es portador de la añoranza culpable, típicamente burguesa, como le sucediera a Wilde, que terminó considerado un paria, un traidor, tránsfuga de los valores más nobles y sublimes de la burguesía victoriana.

Pero existe además una nostalgia revolucionaria, teñida de un afán de futuro que sólo puede construirse desde el presente. Es la nostalgia del texto, de la acción y del guerrillero. Una añoranza tan concreta y tangible como para mantener en jaque al gobierno colombiano, por ejemplo. En América Latina, las revoluciones no se hacen a partir de entelequias. Pero este es un punto de vista que ampliaremos en el apartado siguiente, cuando hablemos de objeto de nostalgia y sujeto nostálgico.

\section{OBJETO DE NOSTALGIA Y SUJETO NOSTÁLGICO.}

Hablemos un poco del Che Guevara y otras especies parecidas. Cuando recordamos la revolución estudiantil de Francia y México en 1968, de las protestas y la rebeldía contra la guerra de Viet-Nam en los Estados Unidos, de las reacciones mundiales contra la invasión a Checoslovaquia, ¿es la nostalgia del ideal la que nos sobrecoge? El objeto de nuestra añoranza, ¿es el contexto?, ¿son los héroes, las convicciones, la capacidad de lucha? Si bien la nostalgia imperialista pareciera tener muy claro cuál es su objeto, y cuál el sujeto nostálgico (recordemos a Rudyard Kipling y el imperialismo británico, por 
ejemplo), para la nostalgia anti-imperialista y revolucionaria el asunto se manifiesta un poco menos claro.

Porque no podemos afirmar que Fidel Castro sea un líder revolucionario abrumado por la nostalgia y la frustración. Si alguien está bien asentado sobre la realidad de América Latina y de su país, ese es precisamente el dirigente cubano. No obstante, alguna gente insiste en referirse a él como un político nostálgico, mucho más articulado a los ideales del pasado, ésto es del comunismo soviético, que a las realidades y retos del presente en su país. Pero, más bien pareciera que, quienes están combatiendo a los fantasmas del pasado, son los agentes del imperialismo. El socialismo cubano, de fuerte inspiración martiana y bolivariana, siempre ha estado ahí. Lo que es nuevo, con la guerra fría y la intolerancia del gobierno de los Estados Unidos, es el bloqueo, que ahora se ha quedado sin sustrato político e ideológico. La añoranza culpable le pertenece entonces a la potencia norteamericana, puesto que nunca logró doblegar al pueblo cubano.

Pero la nostalgia anti-imperialista tiene otras expresiones, menos contingentes. La mala conciencia en este caso, cuando mucho, se parece más al resentimiento, que a la añoranza culpable del imperialismo. La nostalgia antiimperialista es la nostalgia del futuro. Sólo desde esta perspectiva será posible hablar de Fidel Castro, o del noble Che Guevara, como líderes nostálgicos. Pero están además, los nostálgicos con respecto a ellos.

Quien añora al Che Guevara, quien pretende que con su resurrección los problemas de América Latina se resolverán por una suerte de alquimia 
desconocida, olvida que su ideario sigue vigente. Y este caso sería el único en que la añoranza culpable es posible, puesto que, siguiendo las ideas del Che Guevara, no se hizo lo suficiente para enfrentar al imperialismo en América Latina, que quiere convencernos de que es nostálgico (según su óptica) pensar en eliminarlo de nuestra historia y de nuestro presente.

Para el imperialismo es nostálgico que queramos deshacernos de él. Y está viviendo en otra época, quien se atreve a pensar en un futuro sin guerras, sin hambre, sin opresores, y sin intervenciones extranjeras. Por lo tanto, las FARC en Colombia son nostálgicas, lo son también quienes combaten el bloqueo a Cuba, y se han opuesto a la guerra contra Irak o Kosovo recientemente. En definitiva, como dice un amigo mío, el cinismo del imperialismo no tiene límites ${ }^{5}$. Al final, si el objeto de nostalgia en el discurso imperialista es el paraíso perdido, cuando eran amos y señores absolutos de hombres y pueblos enteros, el sujeto nostálgico es aquel que cree (como Reagan una vez) que los escenarios no cambian, y que los hombres menos. Puesto que el fracaso del socialismo real es en realidad el éxito de quienes, después de tal experiencia, han logrado precisar mejor que nunca al enemigo que hay que combatir. Si al fin el capitalismo ha logrado imponerse por completo, entonces carece de lógica la nostalgia

${ }^{5}$ CEDEÑO CASTRO, Rogelio. El 98 y el cinismo del imperio. En VARIOS AUTORES. EL 98 HISPANOAMERICANO. Memoria del Coloquio sobre el 98 realizado por el Centro de Estudios Generales de la Universidad Nacional de Costa Rica, en diciembre de 1998, y en conmemoración del número 50 de los plegables publicados bajo el título de TÓPICOS DEL HUMANISMO (Heredia, Costa Rica: EUNA. Junio de 1999) PP. 33-38. 
imperialista. Pero es que, en el fondo, los ideológos de ésta no han acabado por aceptar aquella supuesta victoria. Aún dudan de ella. Ahí reside su añoranza culpable. En que no se hizo lo suficiente para arrasar con la revolución cubana (como cierta vez me dijo una estudiante norteamericana), en que no se pudo ganar la guerra de Viet-Nam, en que no se alcanzó a convencer a los chinos de destruir al socialismo soviético, en que no se logró la anexión de México. Entonces, ¿el imperialismo sigue vigente? Por supuesto, en la medida en que aquellos objetivos no se hayan concretado, la agenda sigue abierta y dispuesta a recibir nuevas propuestas, como ya sucedió con Irak y Kosovo.

La nostalgia por el buen salvaje, sumiso, obediente y servidor de su señor colonialista, aunque la palabra nostalgia haya sido originalmente pensada en el siglo $\mathrm{XVII}^{6}$ y para propósitos muy específicos, tiene el mismo poder de invocación imperial que tuvo entonces. Como nos lo sugiere Marshall Berman, la ideología del progreso no puede ser mejor que las prácticas de muerte ejercidas por el buen salvaje a que hacíamos referencia ${ }^{7}$. Lo fáustico no puede reemplazar a lo tanático. El rito conjura la divinidad pero no es su depositario.

La nostalgia revolucionaria, que es nostalgia de futuro, no es portadora de añoranza culpable, aunque podría serlo en el momento en que la nostalgia productiva de la utopía desapareciera.

\section{LA NOSTALGIA PRODUCTIVA.}

\footnotetext{
${ }^{6}$ ROSALDO, Renato. Op.Loc.Cit.

${ }^{7}$ BERMAN, Marshall. TODO LO SÓLIDO SE DESVANECE EN EL AIRE. LA EXPERIENCIA DE LA MODERNIDAD. (México: Siglo XXI editores. 1989) Capítulo 1.
} 
La nostalgia revolucionaria, anti-imperialista, es nostalgia productiva. Porque no se agota en el simple añorar, no se agota en la culpa disimulada que está detrás de la nostalgia imperialista. Esta última se disolvió en su anhelo de nobleza. Aquella se potencia con el anhelo de utopía.

La nostalgia revolucionaria, la del rebelde, el decadente y el marginal, es el tipo de nostalgia que es portadora de iconografía e iconoclasia al mismo tiempo. Este tipo de paradojas, como venimos sosteniendo, son las que nutren las distintas nostalgias de nuestra cultura. Es difícil imaginar a los Beatles, a Warhol, y a Marilyn Monroe, sin Kennedy, Krushev o Castro. Este cóctel pudiera tener la apariencia de incoherente y desgajado de la realidad, pero resulta que los ingredientes ideológicos que están detrás de esos nombres, son los pilares de lo que ha perfilado a una cultura de la depresión y la paranoia, como lo es la nuestra.

En esa medida, los trabajos de analistas como Alfred Adler o Karen Horney ${ }^{8}$, son los textos inevitables que produciría una cultura totalmente contaminada por el miedo, la angustia y las ansias evasivas de la mayor parte de las personas.

Al hacer tabla rasa del pasado, la revolución francesa (del siglo XVIII) trajo consigo uno de los factores más decisivos para nuestra comprensión del siglo XX. Nos reveló al individuo, pero nos dejó sin nada del espíritu comunitario de

\footnotetext{
${ }^{8}$ ADLER, Alfred. EL CARÁCTER NEURÓTICO DE NUESTRO TIEMPO (Barcelona: Planeta. 1993). HORNEY, Karen. LA PERSONALIDAD NEURÓTICA DE NUESTRO TIEMPO (Barcelona: Planeta. 1994)
} 
los tiempos medievales ${ }^{9}$. Y con la llegada del individuo, la burguesía nos descubrió la soledad.

El romanticismo de movimientos como los pre-rafaelistas (en la Inglaterra victoriana de los años que van entre 1848 y 1914), cuaja en la nostalgia por la posibilidad de recuperar ese espíritu comunitario. De esta manera, se desprende la conclusión ineludible de que, todo movimiento artístico o intelectual movido por la nostalgia, es al fin y al cabo romántico y revolucionario. Ese es el criterio de verdad de la nostalgia productiva. El vanguardismo de William Morris, Marcel Duchamp y Borges, es un vanguardismo nostálgico, que, a pesar de pertenecer a épocas y movimientos intelectuales distintos, vulnera por igual la cotidianidad del hogar, la galería y el libro ${ }^{10}$. Existe una línea continua entre el papel tapiz de Morris, las instalaciones de Duchamp y los poemas más intimistas de Borges. En estos casos la nostalgia es la brea que cumple el rol de componente articulador de distintas manifestaciones de la cultura, unidas por una misma aspiración de nostalgia revolucionaria.

Alguien podría pensar que el autor de este ensayo está delirando, cuando relaciona a Morris con Borges, pero es que si algo evidencia la lucidez de la burguesía es su democratismo de pastiche, donde distintas expresiones de la rebeldía pueden a la larga coincidir en un mismo propósito: amacizar su dominación.

\footnotetext{
${ }^{9}$ MCLELLAN, David. La concepción materialista de la historia. En HISTORIA DEL MARXISMO. EL MARXISMO EN TIEMPOS DE MARX. (Barcelona: Bruguera. 1979) Tomo 1. Pp. 83-112.

${ }^{10}$ THOMPSON, E.P. WILLIAM MORRIS. ROMANTIC TO REVOLUTIONARY. (Londres: Merlin Press. 1977). MINK, Janis. MARCEL DUCHAMP. EL ARTE CONTRA EL ARTE (Alemania, Colonia: Taschen. 1996). SALAS, Horacio. BORGES. UNA BIOGRAFÍA. (Buenos Aires: Planeta. 1994). 
Ahora bien, si a la nostalgia de pretérito le atribuimos el quietismo, la falta de vitalidad y casi hasta la necrofilia, ¿no estaríamos incurriendo en una contradicción cuando sugerimos que el romanticismo pre-rafaelista por ejemplo, al dejarse tentar por el arte pre-renacentista, es también revolucionario?

La nostalgia que inspira a los pre-rafaelistas es nostalgia de futuro, revolucionaria, rebelde, de cambio; sólo que al servirse del pasado lo hacen con la sabia actitud de quien busca en él lo que falta para completar el presente, y de esta forma transformar el mañana. Los pre-rafaelistas quisieron de esta manera recuperar los afectos que el Renacimiento y la llustración les habían robado. Tanto énfasis en la razón, los hizo revolucionarios de las emociones ${ }^{11}$. Pero resulta que en busca de la naturalidad propia, según ellos, del arte medieval, la burguesía les hizo pagar muy caro su desajuste con el presente, donde ella se desenvuelve con absoluta soltura, puesto que ese es su dominio más preciado, el cual se expresa en el industrialismo, la tecnología, y una soledad gélida. Algunos de esos artistas pagaron con el suicidio, la locura, el alcoholismo y la drogadicción su atrevimiento por olvidarse del presente. No puede ser de otra forma: es en el presente donde se realizan los beneficios, las ganancias, y la plusvalía.

\section{EXPERIENCIA Y REALIDAD DE LA NOSTALGIA.}

¿Cómo se experimenta la nostalgia? ¿Cuál es la realidad de la nostalgia? ¿Es posible el salto cualitativo de romántico a revolucionario, según el buen decir del

\footnotetext{
${ }^{11}$ THOMPSON, E.P. Op. Loc.Cit.
} 
historiador británico Thompson? ${ }^{12}$. ¿No fue eso lo que sucedió precisamente con el Che Guevara?. Esas son algunas de las preguntas fundamentales, aunque no estamos seguros de tener las respuestas correctas.

El colonialista y el imperialista saben muy bien cómo experimentar la realidad de la nostalgia. Charles Degaulle estuvo a punto de perder su gobierno, entre otras cosas, por su imperial terquedad nostálgica, con relación a la guerra por la independencia de Argelia. Lo mismo le sucedió a los ingleses con la India, y a los norteamericanos con Cuba ${ }^{13}$.

Pero al historiador le es permitido experimentar la nostalgia de otra forma. Más todavía si es un historiador plenamente consciente de las potencias de su disciplina de trabajo. Porque sabe que la nostalgia imperialista se concreta en datos muy específicos de momentos ya idos, pero cuya sedimentación en la memoria de los pueblos y de los individuos debe ser utilizada para mantener pujante la posibilidad de volver.

La nostalgia imperialista es de una fuerza ideológica descomunal. En gran medida, las glorias pasadas del imperio británico han servido como un magma, eficaz y positivo, para mantener funcionando a la tambaleante y desprestigiada monarquía. Reagan quiso hacer lo mismo en los Estados Unidos, durante la década de los años ochenta, en un esfuerzo extemporáneo por retener el brillo que alguna vez tuviera el imperialismo norteamericano de los años de la guerra

\footnotetext{
12 Idem. Loc.Cit.

${ }^{13}$ Hemos escrito varios trabajos con relación a este tipo de asuntos. Véase Mark Twain, Cuba, Filipinas y el antimperialismo en los Estados Unidos. En CASA DE LAS AMÉRICAS (Cuba, 1998: No.212) Pp. 104 114. También El antimperialismo a la luz de los héroes del 98: Martí, Hostos, Betances y Sandino. En EXÉGESIS (Puerto Rico: 1998. No. 32) Pp. 21-43.
} 
de Viet-Nam (1954-1975), cuando la arrogancia, la insolencia y la brutalidad eran las soluciones para todo problema que se le opusiera.

El impacto de estos últimos estertores monárquicos en los Estados Unidos, tuvo consecuencias funestas para los pueblos de América Central, por ejemplo. Sin embargo, el imperialismo norteamericano cambió de estrategia, sobre todo en virtud de que, el colapso del socialismo real en Europa central y oriental, no representó necesariamente una consolidación absoluta del capitalismo en esos países, y mucho menos una superación de la crisis general del sistema como totalidad. Este sigue sumido en una crisis de larga duración, con todos los componentes que le son característicos, tales como el desempleo, la bancarrota sindical, la enorme inestabilidad de precios y salarios, violentas caídas de la producción, y un crecimiento espectacular de la tecnología que se concentra en unas pocas manos, con el consiguiente efecto multiplicador en los índices de pobreza, falta de vivienda decente, salud pública efectiva y educación para todos.

La incidencia de la sinuosidad de estos índices en las estructuras democráticas y sobre los mecanismos con que la sociedad civil cuenta para hacerse oír, ha sido de tal magnitud que bien podemos sostener, sin temor a equivocarnos, que en la sociedad capitalista el poder político nunca ha estado tan concentrado y tan mal ejercido como ahora.

Ese tipo de situaciones han hecho factible el renacimiento del nazismo, de los odios raciales, y de un nuevo tipo de guerra en la cual los viejos motivos del imperialismo encuentran razones válidas para sostenerse. La última guerra en 
Kosovo reúne todos los ingredientes de las viejas contiendas en las que se enfrascaba aquél, y ha puesto en evidencia también que las viejas fisuras entre sus distintas expresiones geográficas o regionales no han sido resueltas.

Por eso es que, nada es más ideológico en el capitalismo contemporáneo que la nostalgia imperial. Está repleta de símbolos, de rituales y ceremonias mediante las cuales se busca invocar las glorias del ayer, y sobre todo, impedir que las emociones, las ideas y los sentimientos que trae consigo toda aquella parafarnelia, se nos vaya de las manos, para no volver jamás. Hay autores que han hecho eso de una manera impecable, tal es el caso otra vez, de Rudyard Kipling, el escritor inglés ganador precisamente del Premio Nobel de 1907, por su clara y contundente defensa de los sueños y obligaciones de la carga del hombre blanco inglés, es decir de sus responsabilidades para civilizar a los salvajes de la India, China, Africa y América ${ }^{14}$.

Pero el colonialista por ejemplo, primero destruyó y después extrañó. Es la paradoja que, sin sonrojarse, le produce la indecisión entre destruir la vieja y madura sabiduría hindú, o de inmediato pasar a su extrañamiento y su añoranza. Al salvaje se lo hecha de menos una vez que se lo ha asesinado, que se ha quemado su casa, se ha eliminado su familia, y toda su forma de vida. Como se puede notar, la nostalgia imperial tiene colores fuertes y un intenso sabor a necrofilia.

Entre tanto, las víctimas de este tipo de nostalgia han desarrollado la suya, en la cual no tiene cabida una obsesión improductiva por el pasado. Y no se trata de 
la víctima simple y plena, del sufriente inveterado, sin dirección ni propósito. No, nos referimos al sujeto-objeto de la nostalgia imperial, aquel que sufre y llora, pero también combate, lucha y se desangra para no perder la identidad ${ }^{15}$. Por eso es que, toda discusión sobre este tema, no puede quedarse en el snobismo angustiante del que tiene respuestas para todo, aunque éstas sean las de Nostradamus. Si ese hubiera sido su enfoque de la cuestión, Octavio Paz jamás hubiera escrito EL LABERINTO DE LA SOLEDAD ${ }^{16}$. Porque si alguien nos ha enseñado cómo se obtiene lo mejor de la nostalgia de futuro, ese fue Paz. Toda su obra fue un recurso efectivo para comprender el pasado y para plantearse la posibilidad real de un mejor mañana. Esa visión productiva del ayer nos deja sin víctimas ni victimarios, el nutriente de los enfoques fanatizados y furibundos. Pero nos revela una vereda iluminada y vigorosa, la del que ve en la nostalgia y la melancolía del porvenir la manera más eficaz de remontar los sueños en sí mismos, para convertirlos en instrumentos bien aguzados con la idea de modificar el presente. Sólo así podría hablarse de transformar el futuro. Pero para ello se requiere imaginación utópica.

\section{UTOPÍA Y PRÁXIS DE LA NOSTALGIA.}

Hay dos autores que, no por diferentes en su estilo y en sus preocupaciones, deberíamos estar releyendo. Uno es Karl Marx y el otro es Octavio Paz. Alguien

\footnotetext{
${ }^{14}$ Un texto nuestro que está en prensa titulado 1898-1902. ENSAYOS SOBRE LA GUERRA HISPANOANTILLANO-NORTEAMERICANA, discute en uno de sus capítulos el contenido ideológico de la nostalgia imperial de Kipling y sus seguidores.

${ }^{15}$ Valdés, Adriana. Luces Bajas. En FORO CULTURAL IBEROAMERICANO A DISTANCIA. GLOBALIZACIÓN E IDENTIDAD NACIONAL. 1998. (Chile: MAV. Canal Cultural) http://www.mav.cl/canalcultural/foro_cult/valdes.htm

${ }^{16}$ PAZ, Octavio. EL LABERINTO DE LA SOLEDAD (México: FCE. 1989). 
políticamente muy mojigato podría argumentar que no hay relación posible entre ambos pensadores. Nosotros creemos que sí la hay, al menos en lo que se refiere a la agudeza con que hicieron y rehicieron las crónicas de sus tiempos. Porque si hubo un excelente cronista de su época, ese fue Karl Marx. Sus escritos sobre la situación política en Francia, Alemania, los Estados Unidos, España, la India, América Latina y Rusia, así como los de su inseparable amigo, Frederick Engels, son verdaderas cajas de herramientas analíticas para nuestra mejor comprensión del presente. Tal es también el caso de Octavio Paz, el iluminado profeta de su siglo. No obstante, este es un autor que presenta la rara particularidad de que sus conclusiones no siempre coinciden con las premisas de las que parte. El soporte analítico, con una factura literaria exquisita y de extraordinaria potencia explicativa, arriba con frecuencia a conclusiones en las que uno cree haber encontrado respuestas para ciertos problemas, y de pronto se encuentra con la sorpresa de que más bien se le han llenado las manos de más preguntas sin solución. Si en algo nos ayudó Octavio Paz para comprender el siglo veinte fue en haber planteado algunas de las preguntas correctas. No tanto en haber brindado las respuestas. Es que ni las revoluciones nos han dado las respuestas que andábamos buscando.

Después de la caída del socialismo real nos ha llegado al escenario otro tipo de nostálgicos. Una clase que nada tiene que ver con Marx y sus teorías. Por eso sostenemos que a éste hay que volver a leerlo. Entendiendo que la relectura de Marx debe ser hecha con la responsabilidad militante de quien sabe que el filósofo alemán sigue perteneciendo al porvenir y no al ayer. 
Sepultar a Marx fue la propuesta que hiciera alguna intelectualidad aburguesada y vergonzante, que se sirvió de él cuando su neurosis y su nivel de frustración material se habían hecho intolerables. La caída del socialismo fue la excusa perfecta para legitimar ante sí mismos la necesidad de cinismo que tenían atragantada hacía rato. Es entonces cuando nos damos cuenta que la desaparición del proyecto socialista produjo dos tipos de resentidos. Y aunque el resentimiento es un ingrediente fundamental para que la nostalgia tenga cuerpo, un resentido y un nostálgico no son lo mismo. Al resentido lo mueve la amargura y el desamor. Es víctima de su presente. Al nostálgico lo conmueve la utopía, ya sea de pasado o de futuro, pues el presente no lo apremia, aunque lo angustia. Tenemos entonces al resentido que perdió el olfato para detectar por dónde iba la historia, por un lado. Y por el otro, al resentido que se quedó atorado en el pudo haber sido y no fue. Para el verdadero nostálgico el resentimiento no es un problema, es sólo una excusa para encontrar el puente que una vez unió al éxtito con el fracaso. Un puente que la realidad hizo saltar en pedazos.

Por eso es que hay que volver a los demiurgos, como Karl Marx, Marcel Proust, Oscar Wilde, José Lezama Lima, Octavio Paz o Jorge Luis Borges. Todos ellos son prestidigitadores de la realidad. Su oficio es la magia. Y sólo mágicamente, utópicamente, se puede volver a tender aquel puente que mencionamos atrás.

La relectura de estos autores es un dispositivo central en la comprensión de la equidistante lejanía entre nostalgia y utopía. Pues resulta que el nostálgico es un soñador. El que descubre, como ya lo hiciera Proust, que son los sueños los que nos descifran el enigma de lo real. El derecho a la nostalgia nos lo ganamos 
cuando comprendemos que podemos cambiar eso. Cuando pasamos de ser sus víctimas a ser sus creadores; y la nostalgia sólo nos anuncia que los sueños están en reposo. De esta manera descubrimos que Marx está más vivo que nunca, que el encuentro entre el socialismo soviético y él fue simplemente una gran ironía, una broma descomunal de la historia. El salto de la tragedia a la comedia, como él mismo hubiera dicho.

\section{BALANCE FINAL.}

Nos corresponde ahora, ofrecer un menú para el buen y noble nostálgico que pueda haber en cada uno de nosotros. Y le recomendamos tomar conciencia de la mayor paradoja de todas: si el sujeto nostálgico vive su experiencia desde el pasado o hacia el futuro, porque le tiene miedo al presente, la nostalgia sólo es posible en el aquí y el ahora. Cada nuevo día trae su propia cuota de angustia, y con ella es suficiente.

1. No es posible la nostalgia sin sus paradojas. Son ellas las que le dan sentido a nuestra lucha cotidiana. La nostalgia es el reflejo más exacto que tenemos de nuestras frustraciones. $\mathrm{Y}$ creemos que son pocos los autores que han logrado pintar ésto mejor que algunos escritores portugueses. Basta recordar

a maestros como Fernando Pessoa o José Saramago. Con ellos la melancolía es un programa de vida. La nostalgia es el nombre de su estética.

2. El poeta, el novelista, el hombre cotidiano, son sujetos sólidos y evanescentes al mismo tiempo, de la nostalgia como componente vertebral de la cultura occidental. Es curioso, pero para los chinos por ejemplo, los 
antepasados pueden terminar siendo fantasmas molestos y obstaculizadores del crecimiento de los vivos ${ }^{17}$. El mausoleo donde estuvo enterrado por cerca de dos mil años el primer emperador Chin, responsable de haber unificado a lo que hoy es esa nación, ha permanecido sin ser abierto desde 1974, cuando un campesino lo descubriera casualmente. Ellos creen que de ser investigado por arqueólogos dicho mausoleo, el emperador resucitará y les hará la vida un infierno. En Occidente, el hombre más bien necesita de sus fantasmas. Los añora.

3. Es por eso que el sujeto nostálgico, si no tiene o no encuentra los objetos de su nostalgia, se los inventa. Para eso tiene la razón, el razonamiento y todo tipo de racionalizaciones de su cotidianidad. Freud ayudó enormemente en ese sentido ${ }^{18}$; porque si en algo fue decisivo el psicoanálisis fue en el auxilio que le prestó a los individuos en Occidente para que enfrenten sus propias nostalgias, y puedan tolerar la carga de sus particulares cotidianidades.

4. De tal manera que al descubrir la textura del material con que están hechas nuestras nostalgias, los métodos como el de Marx o el de Freud, nos han ayudado también a transformarlas en capacidades productivas conducentes a la realización de nuestros sueños, con los pies bien puestos en el suelo. Toda utopía, nos enseñaron, para que tenga el carácter de tal, debe estar ajustada con armonía a la realidad.

\footnotetext{
${ }^{17}$ CARMODY, Denise y John. LOS GRANDES MAESTROS DE LA HUMANIDAD. BUDA, CONFUCIO, JESÚS Y MAHOMA. VIDA, ENSEÑANZAS Y MENSAJE (Barcelona: Robin Books. 1995).

${ }^{18}$ FROMM, Eric. GRANDEZAS Y LIMITACIONES DEL PENSAMIENTO DE FREUD (México: Siglo XXI editores. 1997. 10a. edición.) Introducción.
} 
5. Y la realidad sólo tolera lo que procede de sí misma, sean sueños, utopías o experiencias simplemente. La experiencia de la nostalgia, es la de ese lado de lo real al que sólo se puede llegar a través de los sueños. Los muy osados, los que se han atrevido a imaginar esos puentes, y también los han cruzado.

6. En estos casos, la utopía es el programa que conduce hasta ahí. Un ser humano nostálgico es aquel que ya entendió que la fantasía se teje en los telares de la cotidianidad. Lo que estamos diciendo, y lo que hemos venido sosteniendo hasta ahora, es que la nostalgia productiva sólo se fragua en el presente. Un individuo nostálgico es un individuo que está muy vivo, porque ya comprendió que la única vida que puede cambiar es la suya, ya sea con el método de Marx, Freud, Proust o Wilde. Todos los caminos de la fantasía y de la nostalgia pueden conducirlo a un solo sitio, su propio corazón. En Occidente estamos, desde hace siglos, tratando de encontrar esos caminos. Alguien voló los puentes, y no hemos podido recuperarnos de ese trauma. La nostalgia es sólo el síntoma.

San José, Costa Rica, julio de 1999. articulos en diversas revistas del continente. Tiene publicados varios libros sobre historia económica y social de América Latina y el Caribe. 